\title{
Determination of the Sufficient Inductance of AC Line Reactor at the Input of Frequency Converter
}

\author{
M Yu Pustovetov \\ Federal State Institution of Higher Education, Russian University of Transport, 9 Obrazcova Str., Moscow, \\ 127994, Russia \\ E-mail:mgsn2006@rambler.ru
}

Received: 4 April 2019; Accepted: 25 April 2019; Available online: 30 May 2019

\begin{abstract}
This article discusses the problem of sufficient inductance of AC line reactor at the input of frequency converter. Author provided some simulations for frequency converter loaded by induction motors with different rated powers. For all induction motors the following characteristics of phase current consumed by frequency converter from the grid considered. Instantaneous peak current during the frequency acceleration of induction motor. Amplitude of the current in steady state mode after the end of induction motor acceleration. Instantaneous peak current during additional charge of DC-link capacitance through the shunting contact of charging resistance. Instantaneous peak current when charging DC-link capacitance through the charging resistance - the most stable characteristic, which is practically does not depend on the presence and nominal of the line reactor. It is advisable to demand to inductance of the line reactor, that is, to percent impedance or short-circuit voltage, $\%$, that the considered in computational experiments peak and amplitude values of currents remain not higher than the last above mentioned. It can be stated that with the increase of induction motor rated power, the sufficient value of short-circuit voltage, $\%$, also increases.
\end{abstract}

Keywords: AC line reactor; Frequency converter; Percent impedance; Inductance.

\section{Introduction}

Frequency Converter (FC) for feeding three-phase induction motors (IM) today is a mass-used device in automation systems of various technological processes. Most often we can see FC with DC voltage link. They consist of full-bridge six pulse diode rectifier, L-shaped low pass filter with inductance $L_{d}$ in the longitudinal branch and capacitance $C_{d}$ in the cross branch, full-bridge IGBT autonomous voltage inverter with PWM (see Figure 1). During FC turn-on to voltage the initial charge process of capacitance $C_{d}$ starts through charging resistance $R$, which will be shunted by switch $K$ after some time. This time duration is sufficient to achieve a voltage value close to the nominal voltage on the capacitor. After that through $K$ will be took place additional charge of $C_{d}$, at the end of which we can start the supply voltage from the autonomous voltage inverter to load. Let the FC be powered by a symmetrical three-phase voltage source with a frequency of $50 \mathrm{~Hz}$ and a line-to-line RMS voltage of $380 \mathrm{~V}$. An AC line reactor $L$ connected to each phase at the rectifier input. FC loaded by threephase IM designed for a rated frequency of $50 \mathrm{~Hz}$ and a line-to-line RMS voltage of $380 \mathrm{~V}$.

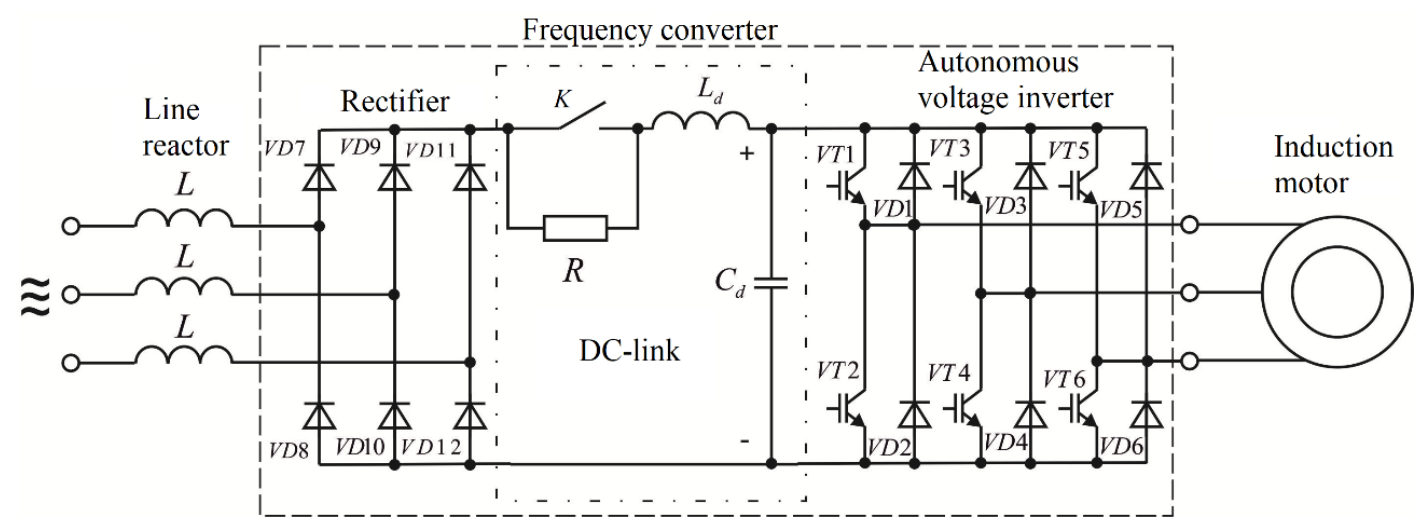

Figure 1. The scheme of power part of VVVF drive 
Manufacturers recommend percent impedance (short-circuit voltage $v_{s c}, \%$ ) for AC line reactors in the range of 2 $\ldots 5 \%$ of the rated phase voltage [1-5]. The line reactors produced by industry meet these requirements $[6,7]$. Manufacturers recommend when powered the FC group from the single power supply to equip every FC by individual line reactor, matching continuous current, and not use the single line reactor for an entire group of FC [7]. This is explained in such a way that at a partial load (if not all FC in the group are turned-on), the single line reactor to the group will not be able to perform its functions satisfactorily. On the other hand, the installation of individual line reactors for each FC is always more expensive than a single reactor for a group of FC. Let us turn to the data, published by Russian sellers of line reactors rated to currents of $2 \ldots 250 \mathrm{~A}$ and a three-phase line-to-line voltage $400 \mathrm{~V}$. In 2018 the dependence of price $P$, rubles, of line reactor rated to current $I$, A (current consumed by one phase of FC) can be described by the expression $P=237.58 \cdot I+1301.9$. It is a straight line. We can make a comparison of the rated power of supplied IM with the consumed current and power of FC, for example, using data published in [8]. Let we have a group consisting of seven FC, each of which feeds the IM rated for $1.5 \mathrm{~kW}$. The seven line reactors, rated for current of $6 \mathrm{~A}$ each, will cost 1.8 times more expensive than a single reactor of $40 \mathrm{~A}$. Or 1.5 times more expensive than a single reactor rated for $50 \mathrm{~A}$.

\section{Simulation conditions}

A unified characteristic of an inductance value (including line reactors which used at the FC input at different rated powers of IM) can be recognized as percent impedance (short-circuit voltage $v_{s c}, \%$ ). Author has provided computational experiments for IM with rated power of $1.5 \mathrm{~kW}, 40 \mathrm{~kW}$ and $110 \mathrm{~kW}$.

For the purposes of simulation, parameters of DC-link of FC depending on the rated power of IM calculated in accordance with the trends equations in Figure 2. Author know data in Figure 2 from practice, and from publication [9]. The mathematical model of IM published in [10, 11], implemented by means of PSpice [12-15], was used.

\section{Simulation results}

We should recognize the inappropriateness of line reactors use in case of DC choke $L_{d}$ presence (Figure 3) [5]. Therefore, we consider the question of sufficient inductance of line reactors for the case of DC choke $L_{d}$ absence (Figures 4-6). For all IM the following characteristics of phase current consumed by FC from the grid considered (see Figures 3-6). Instantaneous peak current when charging through the charging resistance (curve 1). Instantaneous peak current during the frequency acceleration of IM (curve 2). Amplitude of the current in steady state mode after the end of IM acceleration (curve 3). Instantaneous peak current during additional charge of $C_{d}$ through the shunting contact of charging resistance (curve 4). In Figures 3-6 as reference values for the above mentioned currents the values of the 1 st harmonic of phase current consumed by FC in steady state mode after the end of IM acceleration are taken.

The simulation results have shown that the most stable characteristic of the current consumed by FC from the grid is the instantaneous peak current when $C_{d}$ charging through the charging resistance. It practically does not depend on the presence and nominal of the line reactor. It is advisable to demand to inductance of the line reactor, that is, to $v_{s c}, \%$, that the considered in computational experiments peak and amplitude values of currents remain not higher than the last above mentioned.
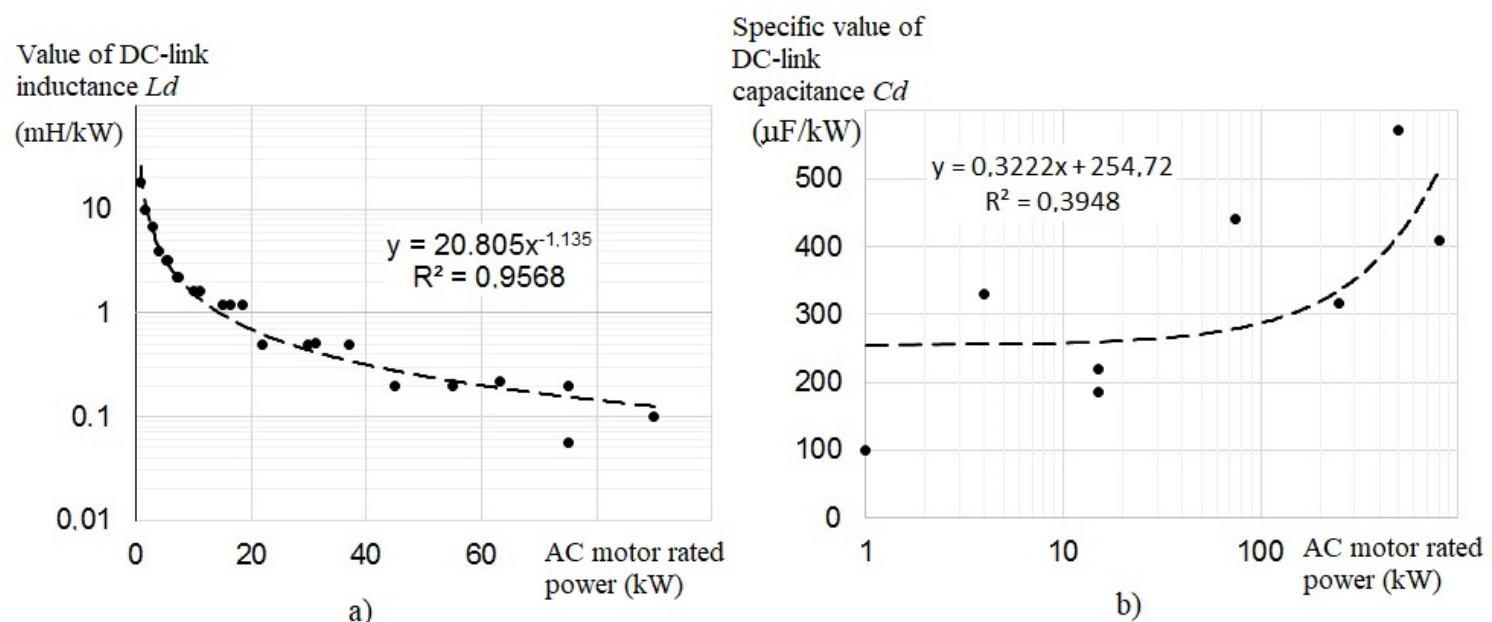

Figure 2. Approximate dependence of the parameters of FC DC-link depending on the rated power of AC motor: a) value of $L_{d}$; b) specific value of $C_{d}$ 


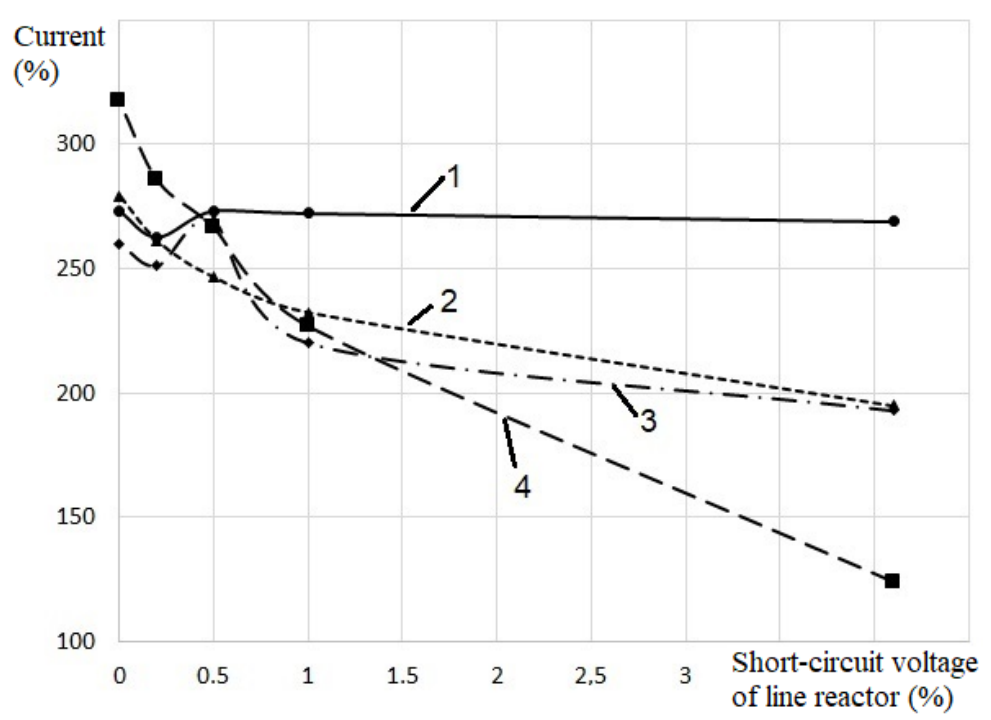

Figure 3. The calculated values of currents in case of $L_{d}$ presence, when IM rated to $110 \mathrm{~kW}$ powered from the FC

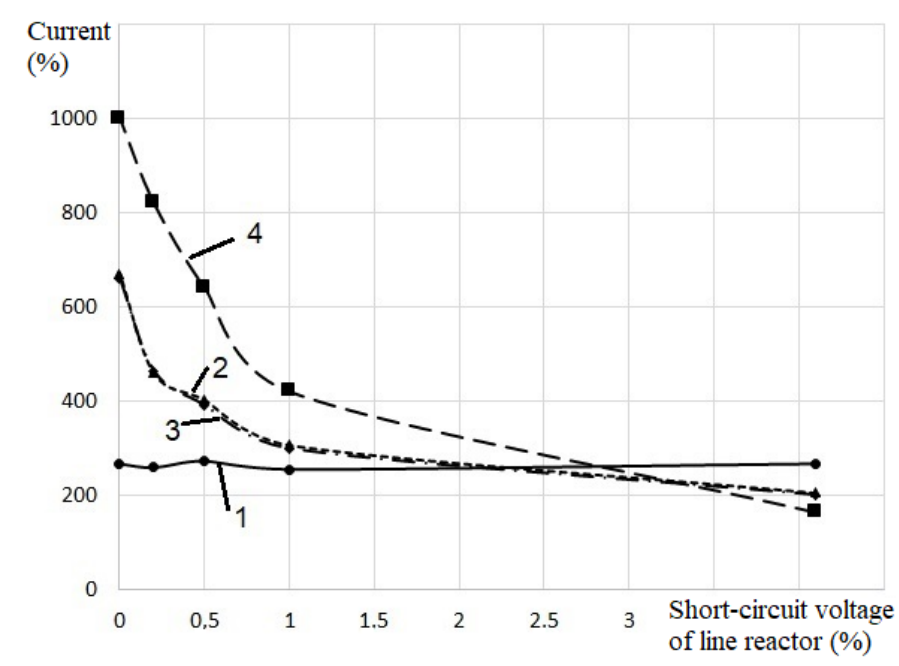

Figure 4. The calculated values of currents in case of $L_{d}$ absence, when IM rated to $110 \mathrm{~kW}$ powered from the FC

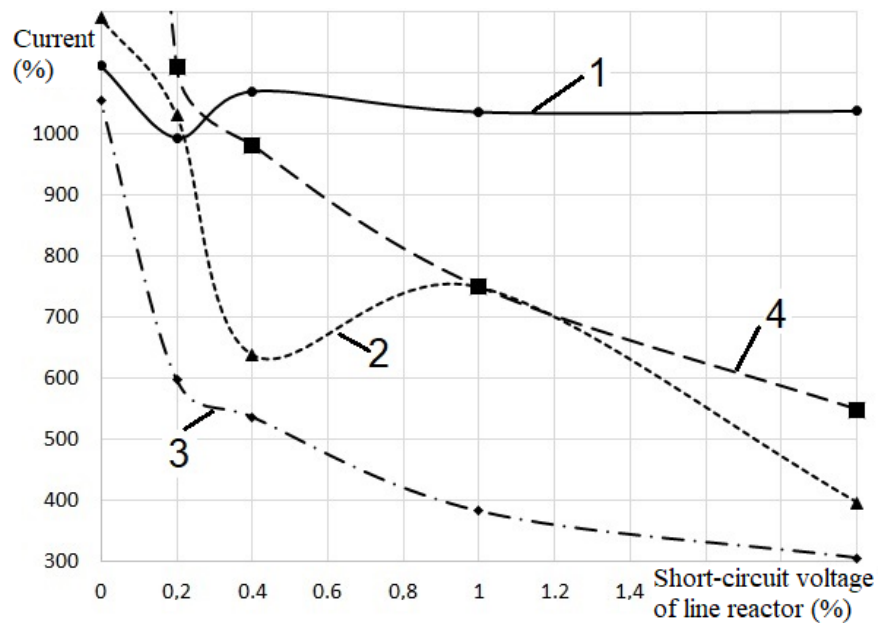

Figure 5. The calculated values of currents in case of $L_{d}$ absence, when IM rated to $1.5 \mathrm{~kW}$ powered from the FC 


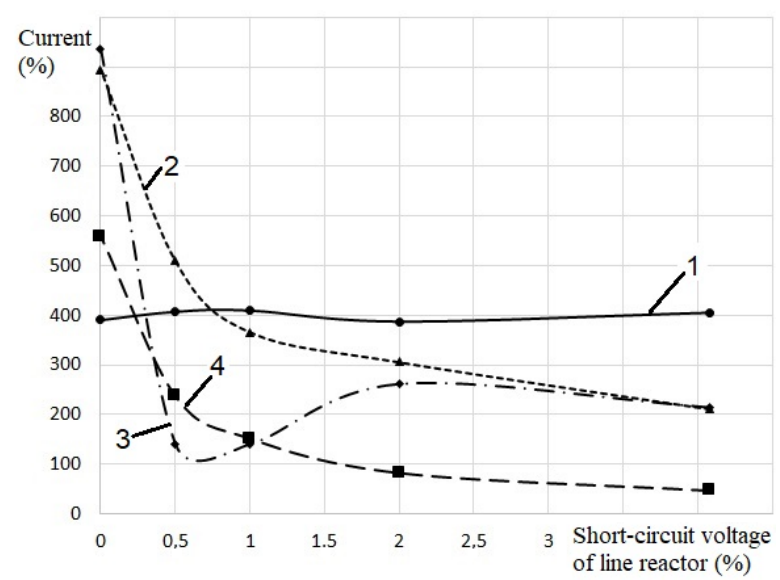

Figure 6. The calculated values of currents in case of $L_{d}$ absence, when IM rated to $40 \mathrm{~kW}$ powered from the FC

In this case, the simulation results can be represented as a curve in Figure 7 (solid line), which shows a sufficient $v_{s c}, \%$ value for line reactor, depending on IM rated power. Also in Figure 7 the approximating equation allowing to calculate sufficient value of $v_{s c}, \%$ is given (dotted line). It can be stated that with the increase of IM rated power, sufficient value $v_{s c}, \%$ also increases.

The value of calculated THD of current consumed by the phase of FC from the grid in a steady state mode after the end of IM acceleration decreases with increasing $v_{s c}, \%$ of line reactor is approximately the same way for all the studied rated powers of IM (Figure 8).

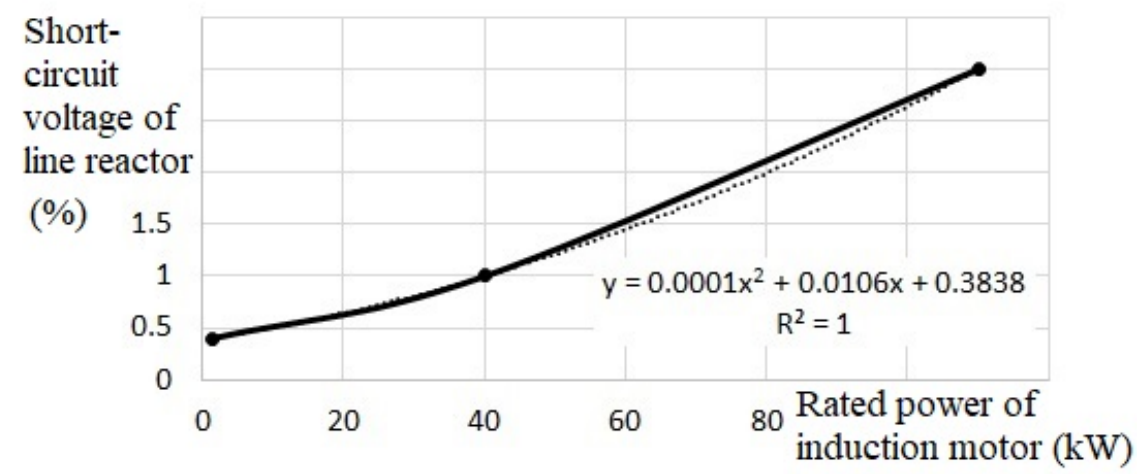

Figure 7. The calculated dependence of sufficient percent impedance (short-circuit voltage $v_{s c}, \%$ ) of line reactor on the rated power of IM, fed from FC in case of $L_{d}$ absence

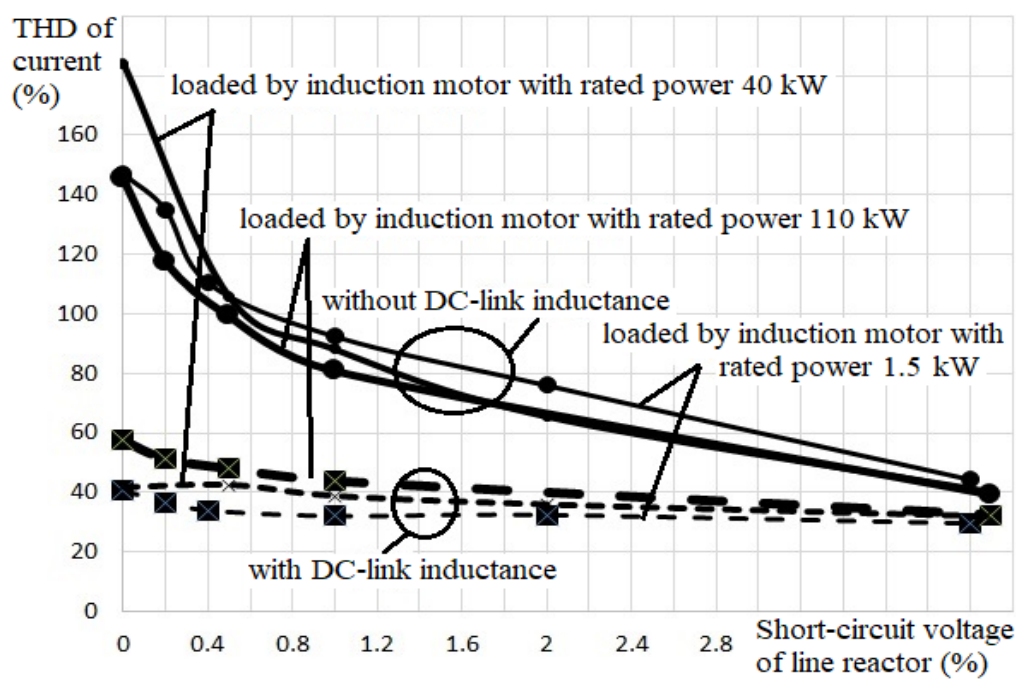

Figure 8 . The calculated THD of phase current consumed by FC from the grid in steady state mode after the end of IM acceleration 


\section{Conclusions}

The most stable characteristic of current consumed by FC from the grid is the instantaneous peak current when charging through the charging resistance. It practically does not depend on the presence and nominal of the line reactor at selected rated power of IM. Because of this it is advisable to demand to inductance of the line reactor, that is, to $v_{s c}, \%$, that peak and amplitude values of current consumed by $\mathrm{FC}$ from the grid at different modes remain not higher than the instantaneous peak current when charging through the charging resistance. Let it be the sufficient value of $v_{s c}, \%$.

The line reactors usage in case of DC choke $L_{d}$ presence is inappropriate.

In case of $L_{d}$ absence it can be stated that with the increase of IM rated power, the sufficient value $v_{s c}, \%$ also increases from $0.4 \%$ for $1.5 \mathrm{~kW}$ to $3 \%$ for $110 \mathrm{~kW}$.

The THD value of current consumed by the phase of FC from the grid in a steady state mode after the end of IM acceleration decreases with increasing $v_{s c}, \%$ of line reactor is approximately the same way for all the studied rated powers of IM.

\section{References}

[1] Umran HM. Parameters identification of a 3-phase LC filter used for variable frequency drive based on practical induction motor testing. Kufa Journal of Engineering. 2015;6(2):76-89.

[2] Sandoval G, Houdek J. A Review of Harmonic Mitigation Techniques. http://www.apqpower.com/assets/files/AReviewOfHarmMitigTech.pdf.

[3] Hoevenaars AH, Fahrney M, James M, McGraw M. Design considerations when applying various ASD topologies to meet harmonic compliance. In: 2010 Record of Conference Papers Industry Applications Society 57th Annual Petroleum and Chemical Industry Conference (PCIC). IEEE;2010. p. 1-9.

[4] Evans IC, Al Khaimah R. The importance of acceptable electrical power quality to the drilling industry worldwide. In: SPE/IADC Middle East Drilling Technology Conference \& Exhibition. Society of Petroleum Engineers; 2013.

[5] Streicher J T. Line Reactors and AC Drives. https://literature.rockwellautomation.com/idc/groups/literature/ documents/wp/drives-wp016_-en-p.pdf.

[6] LR3 400 Netzdrossel, dreiphasig. https://www.block.eu/de_DE/produkte/drosseln-filter/netzdrosseln/.

[7] Lenze AC Tech. Application note. When to use a line or load reactor protecting the drive or the motor. https:/www.rae.ca/wp-content/uploads/Line\%20Reactor\%20White\%20Paper\%20AN0032.pdf.

[8] Variable speed drives Altivar 61 and Altivar 61 Plus for asynchronous motors from $0.75 \mathrm{~kW} / 1 \mathrm{HP}$ to 2400 kW. Catalogue April 2014. https://stevenengineering.com/tech_support/PDFs/45_ALTIVAR-61-PLUSVARIABLE-SPEED-DRIVES.pdf.

[9] Variable speed drives Altivar 71 and Altivar 71 Plus for three-phase motors from 0.37 to $630 \mathrm{~kW}$. Catalogue Sept. 2011. http://www.otomasyonline.com/Data/SchneiderElectric/SCHNEIDER_ATV71_catalog.pdf.

[10] Pustovetov MY. Approach to Computer Implementation of Mathematical Model of 3-Phase Induction Motor. In: IOP Conference Series: Materials Science and Engineering. 2018;327(2):022085.

[11] Pustovetov MY. A mathematical model of the three-phase induction motor in three-phase stator reference frame describing electromagnetic and electromechanical processes. In: 2016 Dynamics of Systems, Mechanisms and Machines (Dynamics). IEEE;2016. p.1-5.

[12] Keown J. OrCAD PSpice and circuit analysis. Upper Saddle River: Prentice Hall; 2001.

[13] Rashid MH, Rashid HM. SPICE for power electronics and electric power. CRC press; 2005.

[14] Şchiop A, Popescu V. Pspice simulation of power electronics circuit and induction motor drives. Rev. Roum. Sci. Techn. - Électrotechn. et Énerg. 2007;52(1):33-42.

[15] Ben-Yaakov S, Peretz MM. Simulation bits: a SPICE behavioral model of non-linear inductors. IEEE Power Electronics Society Newsletter. 2003:9-10.

(C) 2019 by the author(s). This work is licensed under a Creative Commons Attribution 4.0 International License (http://creativecommons.org/licenses/by/4.0/). Authors retain copyright of their work, with first publication rights granted to Tech Reviews Ltd. 